\title{
Retrospective analysis of breech deliveries in tertiary care center
}

\section{Suneela Mullakkal Sankaran, Jayasree Sukumara Pillai*}

Department of Obstetrics and Gynecology, Government Medical College, Kozhikode, Kerala, India

Received: 24 August 2020

Accepted: 01 October 2020

\section{*Correspondence:}

Dr. Jayasree Sukumara Pillai,

E-mail: drjayasreerajmohan@gmail.com

Copyright: () the author(s), publisher and licensee Medip Academy. This is an open-access article distributed under the terms of the Creative Commons Attribution Non-Commercial License, which permits unrestricted non-commercial use, distribution, and reproduction in any medium, provided the original work is properly cited.

\begin{abstract}
Background: Breech presentation is the commonest malpresentation accounting for $3-4 \%$ of all deliveries at term. The most common cause for breech presentation is preterm delivery. The safest route of delivery for breech had long been a topic of debate and after the results of term breech trial mode of delivery has become abdominal route even in teaching institutions.

Methods: This is a retrospective cross sectional study conducted at department of obstetrics and gynaecology, Government medical college, Kozhikode, for a period of 2 years from 01 January 2016 to 31 December 2017. Mothers with gestational age between 28 weeks to 41 weeks with singleton live fetus with breech presentation who had either vaginal or caesarean delivery were included. The case notes were retrieved from the medical records department.

Results: A total of 823 breech deliveries occurred during the study period. Of the total mothers 429 were primies and 394 were multies. Common causes identified were prematurity, intrauterine growth restriction, uterine and fetal anomalies. Mode of delivery was caesarean in more than $80 \%$ of cases.

Conclusions: Incidence of breech presentation was 3.2\% during the study period. Increasing incidence of caesarean delivery is seen in breech presentation. Persistent breech presentation at term is most commonly seen in patients with associated oligamnios, intrauterine growth restriction, and uterine anomalies.
\end{abstract}

Keywords: Breech, Oligamnios, Intrauterine growth restriction

\section{INTRODUCTION}

Breech presentation represents a challenging vaginal delivery condition, and it is the commonest malpresentation accounting for 3-5\% of singleton fetuses at delivery. Breech presentation results from uterine anomalies, cornuofundal insertion of placenta, placenta previa, oligohydramnios, fetal growth restriction, prematurity, short umbilical cord, fetal anomalies like hydrocephalus, and swellings in front of the neck. ${ }^{1-3}$

Even though breech presentation is usually associated with placenta previa, placenta previa is seen in only very small percentage of breech presentations. The commonest cause is prematurity (around 22\%) as each fetal pole is of similar bulk earlier in pregnancy. Near term the incidence decreases due to spontaneous version to vertex presentation. ${ }^{4}$ It is a high risk pregnancy with adverse fetal outcomes in labour and delivery if it persists as breech presentation. Adverse outcomes in breech deliveries are mainly due to preterm delivery, preterm premature rupture of membranes, intra uterine growth restriction, oligohydramnios..$^{5}$ Though caesarean section for breech is not recommended universally caesarean can reduce the perinatal mortality and morbidity compared to vaginal delivery. ${ }^{6}$

The current obstetrical decisions regarding vaginal delivery of breech fetus has been greatly influenced by results of term breech trial collaborative group of Hannah in the year 2000. Before this study vaginal breech deliveries were the method of delivery. Hannah's study proposed all breech should be delivered abdominally and caesarean delivery was associated with a lower risk of perinatal mortality compared with planned vaginal 
delivery. ${ }^{6}$ Contrary to this, the presentation and mode of delivery study (PREMODA) did not show any differences in corrected neonatal mortality rates and neonatal outcomes according to delivery mode. ${ }^{7}$ Proper patient selection, labour management protocol, fetal monitoring and conduct of labour by an experienced obstetrician and neonatologist, vaginal breech deliveries also can be as safe as abdominal delivery.

Objective of this study was to analyze the common obstetrical characteristics that are associated with breech presentation and fetal outcome at a tertiary care center.

\section{METHODS}

This study was conducted at department of obstetrics and gynaecology, Institute of maternal and child health (IMCH), Government medical college, Kozhikode for a period of 2 years from 01 January 2016 to 31 December 2017. The incidence of breech deliveries, maternal and perinatal outcome were analyzed. The study was a retrospective cross sectional study. Patients with gestational age between 28 weeks and 41 weeks, with breech presentation admitted at the department of obstetrics and gynaecology, were included in this study. Informations were collected from the hospital medical records library, IMCH. Details regarding age, gestational age, parity, and mode of delivery, sex, weight of baby, maternal risk factors, fetal complications, Apgar and neonatal intensive care unit (NICU) admission were collected.

Data was analyzed using statistical package for social sciences (SPSS) 16.0 statistical software-405.

\section{RESULTS}

In this retrospective study 823 cases were studied for a period of 2 years from 01 January 2016 to 31 December 2017. The incidence of breech was $3.2 \%$. From Figure 1 we see that $84.6 \%$ of cases belong to the age group between $20-35$ years. $9.8 \%$ were in the age group less than 20 years and $5.6 \%$ belong to age group above 35 years.

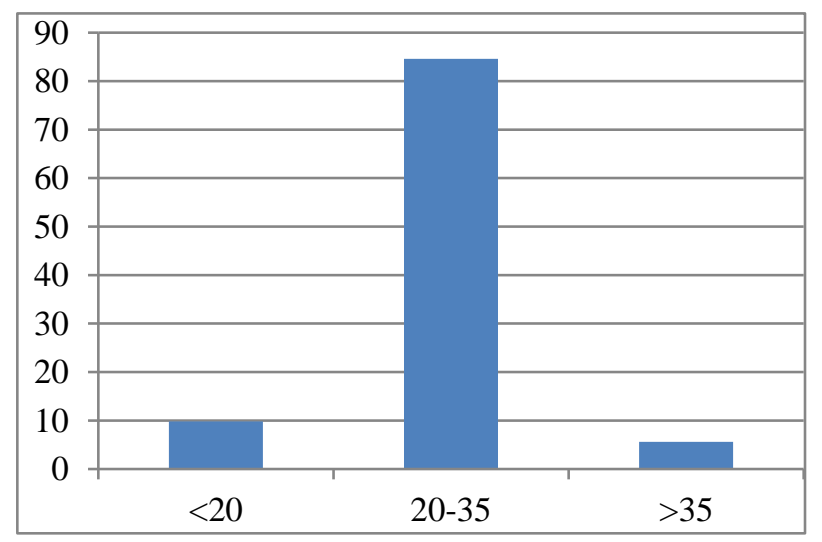

Figure 1: Distribution of breech presentation according to maternal age.
Of the total mothers $52.1 \%$ were primies, $46.3 \%$ were multies, and $1.6 \%$ were grandmulties (Figure 2).

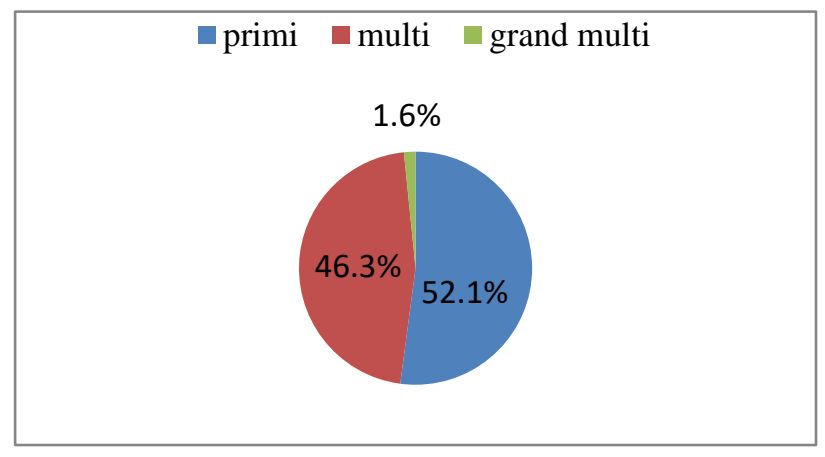

Figure 2: Distribution of breech presentation according to parity.

According to gestational age $64.2 \%$ cases belong to gestational age between $37-40$ weeks, $36.4 \%$ between 28 to 37 weeks and $9.5 \%$ above 40 weeks (Figure 3 ).

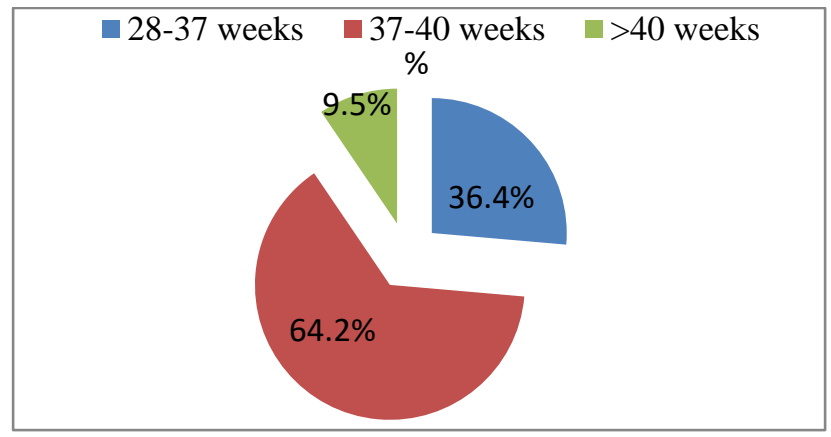

Figure 3: Distribution of breech presentation according to gestational age.

Common causes identified are prematurity in about $26.7 \%$, intra uterine growth restriction in $11.6 \%$, oligamniosin $8 \%$, uterine anomalies in $5.83 \%$ and $7.9 \%$ were associated with fetal anomalies (Figure 4 and 5).

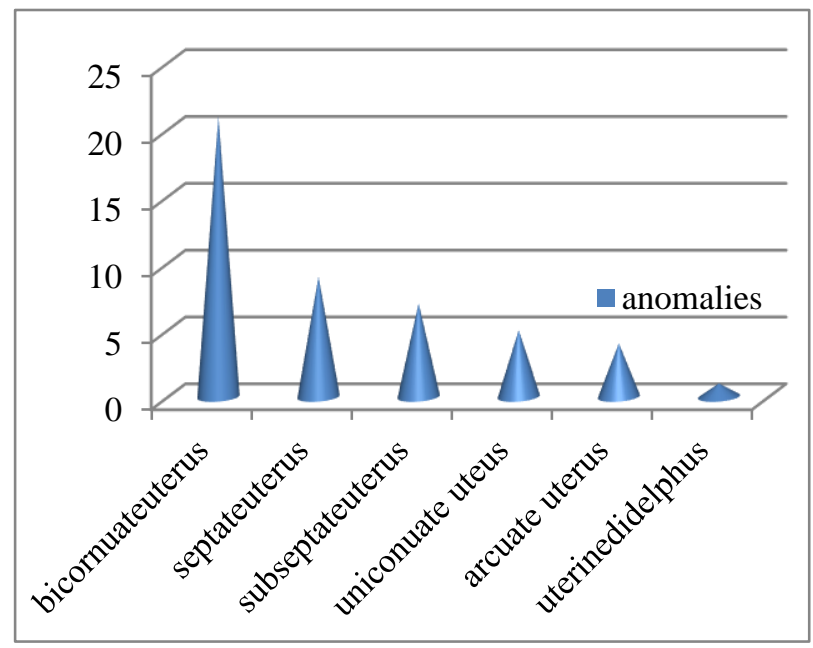

Figure 4: Uterine anomalies in breech presentation. 


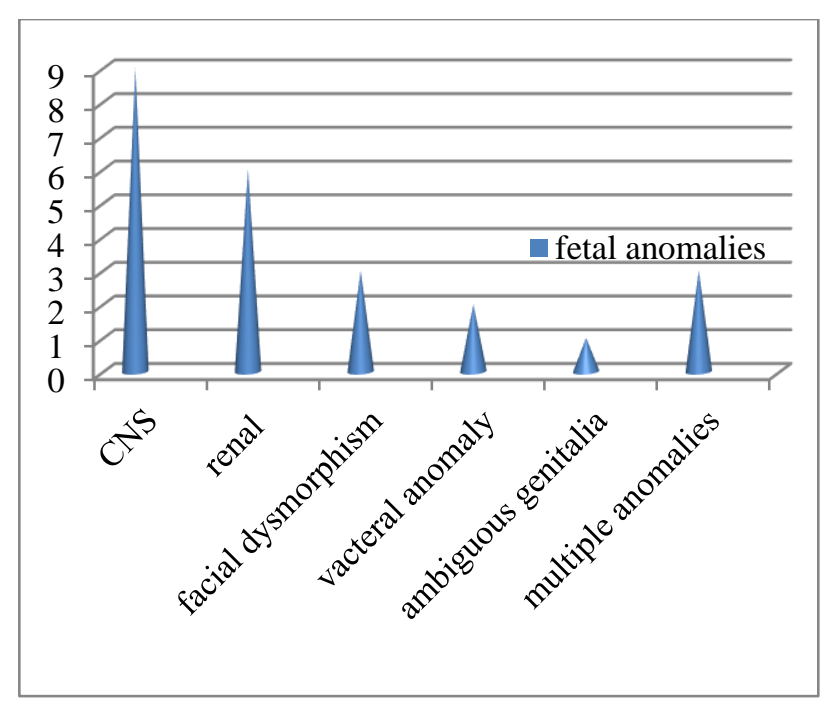

Figure 5: Fetal anomalies in breech presentation.

$81.6 \%$ cases delivered by caesarean section, assisted breech deliveries were of $17.7 \%$ and $0.6 \%$ cases of breech extraction. Of the total caesarean $26.7 \%$ cases done as elective caesarean and $73.2 \%$ as emergency. $33.3 \%$ cases were done for primie breech. Other indications for caesarean section were complicated breech, previous caesarean, breech with premature rupture of membranes etc. Of the total 146 assisted breech deliveries $58.9 \%$ was in multies and $41 \%$ in primies. Gestational age wise $41 \%$ of assisted breech delivery belonged gestational age between 37 to 41 weeks, $34 \%$ between gestational age of 28 weeks to 34 weeks, $23 \%$ between 34 to 37 weeks (Table 1).

The antepartum complications identified were preterm premature rupture of membranes $(4.7 \%)$, premature rupture of membranes $(2.67 \%)$, preterm delivery $(26.4 \%)$, placenta previa $(2.9 \%)$, oligamnios $(8.6 \%)$ and intrauterine growth retardation (11.6\%). Cord prolapse occurred in 5 $(0.6 \%)$ cases. There were 4 cases of caesarean hysterectomy done for associated adherent placenta. Postdated pregnancy in $9.5 \%$. Medical complications associated with the cases studied were gestational diabetes mellitus (11.5\%), gestational hypertension (9.9\%) and anaemia $(0.72 \%)$. There was slight high incidence of postpartum haemorrhage following caesarean. Out of 11 cases of postpartum hemorrhage (PPH) (1.3\%) 9 cases were following lower segment cesarian section (LSCS) and only 2 were after vaginal breech delivery. All cases were of atonic PPH except one case following assisted breech delivery with 3rd degree perineal tear. Complications apart from PPH in LSCS were extension of uterine incision in 3 cases.

There was higher incidence of female fetuses. $57.4 \%$ among the total babies were females and $42.6 \%$ male babies. 55.8\% of babies belong to the group of weight with 2.5 to $3.5 \mathrm{~kg}, 8.5 \%$ babies with weight more than $3.5 \mathrm{~kg}$, $28.9 \%$ with weight between 1.5 and $2.5 \mathrm{~kg}, 6.8 \%$ with less than $1.5 \mathrm{~kg}$ (Figure 6).

Table 1: Distribution of mode of delivery in breech presentation.

\begin{tabular}{|l|llllll|}
\hline $\begin{array}{l}\text { Types of } \\
\text { delivery }\end{array}$ & \multicolumn{2}{l}{ Caesarean section, 672 (81.7\%) } & \multicolumn{2}{l|}{ Vaginal delivery, 151 (18.3\%) } \\
\hline
\end{tabular}

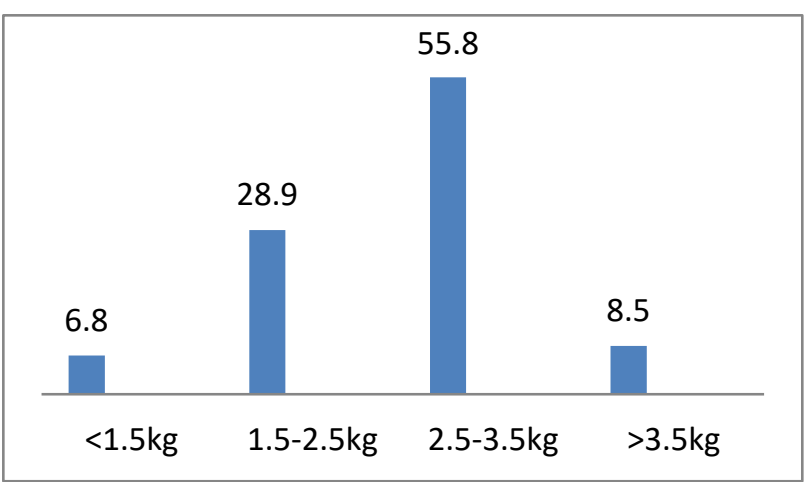

Figure 6: Distribution of fetal weight in breech presentation.

Incidence of neonatal care unit admission was about $21.7 \%$ of which $17 \%$ of the babies stayed for more than 7 days (Table 2).

Of the total babies $9.1 \%$ babies had Apgar less than 7 and $90.8 \%$ babies had more than 7 . Of the total 75 babies with less than 7 Apgar score $86.6 \%$ were with weight less than
$2.5 \mathrm{~kg}$. Among this $50.6 \%$ with weight less than $1.5 \mathrm{~kg}$ that belonging to very low birth weight (Table 3 ).

Table 2: Distribution of neonatal unit stay of babies.

\begin{tabular}{|lll|}
\hline No. of days & No. of babies & Percentage \\
\hline Nil & 644 & 78.2 \\
\hline$<7$ & 39 & 4.7 \\
\hline$>7$ & 140 & 17 \\
\hline
\end{tabular}

Table 3: Distribution of Apgar scores in breech babies.

\begin{tabular}{|lll|}
\hline Apgar & Frequency & Percentage \\
\hline$<7$ & 75 & 9.1 \\
\hline$>7$ & 748 & 90.8 \\
\hline Total & 823 & 100 \\
\hline
\end{tabular}

There were total 8 cases of neonatal deaths. Of that 3 deaths were due to congenital anomalies, 1 due to cord prolapse, 1 due to abruption, 3 due to severe preeclampsia with very low birth weight. 


\section{DISCUSSION}

This study included all the cases of antenatal women admitted beyond 28 weeks of gestation with singleton live fetus with breech presentation. As a routine mode of delivery was caesarean section unless the patient in advanced labour on admission to labour room, or a multigravida with average size fetus, uncomplicated breech, and patient requesting for vaginal delivery. Incidence of breech was $3.2 \%$ which remained similar to the incidence in most of the studies and it is in agreement with the incidence of breech presentation at term. ${ }^{8,9} \mathrm{We}$ have observed an increased association of breech presentation with intrauterine growth restriction and oligohydramnios in this study. ${ }^{10,11}$ Causes identified for breech presentation in this study were primiparity, prematurity, low birth weight, intrauterine growth restriction, oligohydramnios, female sex of the baby, previous caesarean section, congenital anomalies of uterus, leiomyoma, and fetal congenital anomalies. ${ }^{11-13}$ Kalogiannidis et al and Vendettelli et al described that in previous caesarean delivery there is twofold increased incidence of breech presentation. ${ }^{14,15}$ Decreased fetal movements due to intra uterine growth restriction and reduced liquor lead to persistence of breech presentation. ${ }^{16}$

$52.1 \%$ cases were primies. Hehir et al also got similar observation. ${ }^{17}$ The reasons for increased incidence of breech in primies have been thought to be due to tight abdominal wall due to good rectus muscle tone in nulliparous women. Majority of the patients belonged to the age group between 20-35 years. ${ }^{18,19}$ Advanced maternal age there is increasing incidence of breech presentation.

Most of the cases belonged to gestational age between 37 to 40 weeks. For this increased incidence at this gestational age may be because of early admission for elective termination after 39 weeks. Persistent breech presentation at term is an indication for caesarean, and there is no routine external cephalic version done at our center. Majority of babies are of average birth weight. One third of babies belonged to the weight below $2.5 \mathrm{~kg} .{ }^{20}$ This may be due to the association of intra uterine growth restriction $(11.6 \%)$, oligamnios $(8.8 \%)$ and anomalies of uterus. ${ }^{21}$ There is increased incidence of female fetus in this study. Similar observation was also seen in studies by Talas et al and Lutercort et al. ${ }^{22,23}$ Zeitlin et al also had similar observation. Even though exact aetiology is not known for female predominance, several theories are put forward like shorter umbilical cord, and differences in utero motor activity. ${ }^{24}$ Antenatal complications encountered were preterm labour, intrauterine growth restriction and oligohydramnios.

This study shows a very high caesarean rate. ${ }^{25,26}$ Similar to many other studies caesarean rate is almost identical in both primies and multies. Majority of the assisted breech deliveries were in multies and most of them were preterm deliveries. There was slight increased incidence of postpartum haemorrhage following caesarean section. Incidence of gestational diabetes $(11.5 \%)$ and gestational hypertension $(9.9 \%)$ in this study were almost similar to the institutional incidence during the period which was $13.5 \%$ and $10.4 \%$ respectively. ${ }^{27}$ In breech presentation as per se there is no increased incidence of medical complications.

Babies got admitted to NICU were predominantly those who belonged to extreme premature babies and those with severe IUGR. There was not much significant difference in the neonatal morbidity and mortality among the vaginal and caesarean delivery groups. Obstetric risk factors rather than intrapartum events are said to be having a greater role in adverse neonatal outcome..$^{28,29}$

Congenital anomalies of fetus were often associated with breech presentation. Common association were with central nervous system and renal anomalies. Similar observation was seen in this study also. ${ }^{30}$

\section{CONCLUSION}

Incidence of vaginal delivery for breech is decreasing over the years in our institution mainly due to the fear of medical litigation for poor perinatal outcome. LSCS for breech is done routinely because of the lack of experienced obstetricians also. External cephalic version should be attempted under ultrasound guidance in selected cases. Vaginal breech delivery should be a planned one after proper selection of cases, counselling of the patient, and getting written informed consent.

Funding: No funding sources Conflict of interest: None declared

Ethical approval: The study was approved by the Institutional Ethics Committee

\section{REFERENCES}

1. Gunay T, Turgut A, DemirciviBor E, Hocaoglu M. Comparison of maternal and fetal complications in pregnant women with breech presentation undergoing spontaneous or induced vaginal delivery, or cesarean delivery. Taiwanese J Obstet Gynecol. 2020;59(3):392-7.

2. Filipov E, Borisov I, Kolarov G. Placental location and its influence on the position of the fetus in the uterus. Akush Ginekol (Sofiia). 2000;40:11-2.

3. Sekulic S, Ilincic M, Radeka G, Novakov-Mikic A, Simic S, Podogorac J. Breech presentation and the cornual-fundal location of the placenta. Croatian Med J. 2013;54(2):198-202.

4. Luterkort M, Persson PH, Weldner BM. Maternal and fetal factors in breech presentation. Obstet Gynecol. 1984;64(1):55-9.

5. Toijonen A, Heinonen S, Gissler M. Macharey G. Risk factors for adverse outcomes in vaginal preterm breech labour. Arch Gynecol Obstet. 2020. 
6. Hannah ME, Hannah WJ, Hewson SA, Hodnett ED, Saigal S, Willan AR. Planned caesarean section versus planned vaaginal birth for breech presentation at term; a randomized multicenter trial. Term Breech Trial Collaborative Group. Lancet. 2000;356:137583.

7. Goffinet F, Carayol M, Foidart JM, Alexander S, Uzan S, Subtil D, et al. Is planned delivery for breech presentation at term still an option? Results of an observational prospective survey in France and Belgium. Am J Obstet Gynecol. 2006;194(4):100211.

8. Hickok DE, Gordon DC, Milberg JA, Williams MA, Dailing JR. The frequency of breech presentation by gestational age at birth: a large population-based study. Am J Obstet Gynecol. 1992;166(3):851-2.

9. Rauf B, Ayub T. Maternal and perinatal outcome in term singleton breech presentation. J Postgrad Med Inst. 2004;18:373-9.

10. Sherer DM, Spong CY, Minior VK, Salafia CM. Increased incidence of fetal growth restriction in association with breech presentation in preterm deliveries <32 weeks. Am J Perinatol. 1997;14(1):357.

11. Fruscalzo A, Londero AP, Salvador S, Bertozzi S, Biasioli A, Della Martina M, et al. New and old predictive factors for breech presentation: our experience in 14433 single ton pregnancies and a literature review. J MaternaL Fetal Neonatal Med. 2014;27(2):167-72.

12. Zeitlin J, EI Ayoubi M, Jarreau PH, Draper ES, Blondel B, Kunzel W, et al. Impact of fetal growth restriction on mortality and morbidity in very preterm birth cohort. J Pediatr. 2010;157(5):733-79.

13. Cammu H, Dony N, Martens G, Colman R. Common determinants of breech presentation at birth in singletons; a population based study. Eur J Obstet Gynecol Reprod Biol. 2014;177:106-9.

14. Kalogiannidis I, Masouridou N, Dagklis T, Masoura S, Goutzioulis M, Prapas Y, Prapas N. Previous caesarean section increases the risk of breech presentation at term pregnancy. Clin Exp Obstet Gynecol. 2010;37(1):29.

15. Vendittelli F, Riviere O, Creen-Herbert C, Rozan MA, Maria B, Jacquetin B, etal. Is a breech presentation at term more frequent in women with a history of caesarean delivery? Am J Obstet Gynecol. 2008;198(5):521.

16. Harrington K, Thompson O, Jordan L, Page J, Carpentor RG, Campbell S. Obsteric outcome in women who present with a reduction in fetal movements in the third trimester of pregnancy. J Perinatol Med. 1998;26(20):77-82.

17. Hehir MP, O'Connor HD, Kent EM, Fitzpatrick C, Boylan PC, Coulter-Smith S, et al. Changes in vaginal breech delivery in a single large metropolitanarea. Am J Obstet Gynecol. 2012;206(6):498.
18. Zsirai L, Csakany GM, Vargha P, Fulop V, Tabak AG. Breech presentation: its predictors and consequences.An analysis of the Hungarian Tauffer Obstetric Database (1996-2011). Acta Obstet Gynecol Scand. 2006;95(3):347-54.

19. Giri A, Srivastav VR, Suwal A, Tuladhar AS. Advanced maternal age and obstetric outcome. Nepal Med Coll J. 2013;15:87-90.

20. Rayl J, Gibson PJ, Hickok DE. A population -based case-control study of risk factors for breech presentation. Am J Obstet Gunecol. 1996;174:28-32.

21. Olatunji AO, Sule AO. Term breech delivery at a University hospital in Nigeria. Niger Postgrad Med J. 1999;6:171-4.

22. Talas BB, Altinkaya SO, Talas H, Danisman N, Gungor T. Predictive Factors and short -term fetal outcomes of breech presentation: A Case - Control study. Taiwan J Obstet Gynecol. 2008;4(4):402-7.

23. Luterkort M, Persson PH, Weldner BM. Maternal and fetal factors in breech presentation. Obstet Gynecol Res. 2005;31:409-13.

24. Saastad E, Vangen S, Froen JF. Suboptimal care in stillbirths-a retrospective audit study. Acta Obstet Gynecol Scand. 2007;86(4):444-50.

25. Demol S, Bashiri A, Furman B, Maymon E, ShohamVaedi I, Mayzor M. Breech presentation is a risk factor for intrapartum and neonatal death in preterm delivery. Eur J Obstet Gynecol Reprod Biol. 2000;93:47-51.

26. Lee HC, El-Sayed YY, Gould JB. Population trends in cesarean delivery for breech presentation in the United States, 1997-2003. Am J Obstet Gynecol. 2008;199(1):1-59.

27. Toijonen AE, Heinonen ST, Gissler MVM, Macharey G. A comparison of risk factors for breech presentation in preterm and term labor: a nationwide, population-based case-control study. Arch Gynecol Obstet. 2020;301(2):393-403.

28. Newtonraj A, Kaur M, Gupta M, Kumar R. Level, causes, and risk factors of stillbirth: a population based case control study from Chandigarh. India. BMC Pregnancy Childbirth. 2017;17:371.

29. Figueras F, Caradeux J, Crispi F, Eixarch E, Peguero A, Gratacos E. Diagnosis and surveillance of lateonset fetal growth restriction. Am J Obst Gynecol. 2018;218(2):790-802.

30. Mostello D, Chang JJ, Bai F, Wang J, Guild C, Stamps $\mathrm{K}$, Leet TL. Breech presentation at delivery: a marker for congenital anomaly? J Perinatol. 2014;34(1):11-5.

Cite this article as: Sankaran SM, Pillai JS.

Retrospective analysis of breech deliveries in tertiary care center. Int J Reprod Contracept Obstet Gynecol 2020;9:4549-53. 